Proceedings of the Error! Reference source not found. Winter Simulation Conference

Q. Lu, X. Xie, L. Chen, Z. Ye, Z. Fang, J. Meng, M. Pitt and J. Lin, eds.

\title{
CREATING AN INTER-HOSPITAL RESILIENT NETWORK FOR PANDEMIC RESPONSE BASED ON BLOCKCHAIN AND DYNAMIC DIGITAL TWINS
}

\author{
Qiuchen Lu \\ Bartlett School of Sustainable Construction \\ University College London \\ 1-19 Torrington Place \\ London, WC1E 6BT, UNITED KINGDOM \\ Long Chen \\ School of Architecture, Building and Civil \\ Engineering \\ Loughborough University \\ Epinal Way, Loughborough \\ Leicestershire, LE11 3TU, UNITED KINGDOM \\ Zigeng Fang \\ Bartlett School of Sustainable Construction \\ University College London \\ 1-19 Torrington Place \\ London, WC1E 6BT, UNITED KINGDOM
}

Michael Pitt

Bartlett School of Sustainable Construction

University College London

1-19 Torrington Place

London, WC1E 6BT, UNITED KINGDOM

\author{
Xiang Xie \\ Insititute for Manufacturing \\ University of Cambridge \\ Alan Reece Building, 17 Charles Babbage Rd, \\ Cambridge, CB3 OFS, UNITED KINGDOM \\ Zhen Ye \\ Bartlett School of Sustainable Construction \\ / School of Economics \\ University College London / Xiamen University \\ 1-19 Torrington Place / Xiamen \\ London, WC1E 6BT, UNITED KINGDOM / \\ CHINA
}

\author{
Jiayin Meng \\ Bartlett School of Sustainable Construction \\ University College London \\ 1-19 Torrington Place \\ London, WC1E 6BT, UNITED KINGDOM
}

Jinyi Lin

Bartlett School of Sustainable Construction
University College London
1-19 Torrington Place
London, WC1E 6BT, UNITED KINGDOM

\begin{abstract}
This study proposes to develop new knowledge about how to configure digital information for pandemic rapid response, which can use blockchain and digital-driven approaches to facilitate analyses and develop a total solution. Developing and using the rich data implied by dynamic digital twins and blockchain is relevant to manage both patients and medical resources (e.g., doctors/nurses, PPE, beds and ventilators etc.) at the COVID-19 and post COVID period. This paper learns from the experiences of resources deployment/redeployment and pandemic response from UK Hospitals to explore the blockchain solutions for preparing healthcare systems ready for both efficient operation daily and in pandemic thorough (1)
\end{abstract}




\section{Lu, Xie, Chen, Ye, Fang, Meng, Pitt and Lin}

information integration of patient (privacy protected) flow and medical resource flow from healthcare and medical records; (2) optimizing the deployment of such resources based on hospitals, regions and local pandemic levels switching from normal to the outbreak. The main idea is to develop the novel framework for creating an inter-hospital resilient network for pandemic response based on blockchain and dynamic digital twin, which will set up innovative ways to best care for patients, protect NHS staff, and support government scientific decisions to beat COVID-19 now and manage the crisis in the future.

\section{INTRODUCTION}

Since the outbreak of COVID-19, the number of confirmed cases in the UK increased rapidly within a few weeks, reaching 271,222 by the end of May 2020 (UK Government, 2020). This unexpected increase place pressured the National Health Service (NHS) system to be exposed to unprecedented challenges to managing medical resources and patients. Especially at the beginning of the delay phase, the failure of early alert for the upcoming outbreak and the lack of effective management of such two flows (resource flow and patient flow) resulted in the shortage of resources and reduced full capacity of NHS to test, screen, quarantine and treat infected people in the UK (but also around the world). It also tragically resulted in a large number of infected and death cases from NHS staff (over 300 NHS workers have perished in the line of duty (UK's Independent Fact Checking Charity, 2020) and an extremely high mortality rate in patients in the UK (14.06\% by 30 May 2020, 5th highest in the world (UK Government, 2020)).

It is time to review our hospital management system and rethink how to manage the flows of resources and patients in and between hospitals to provide not only effective responses to deal with COVID-19 but early alert of the future pandemic at both local and regional levels. We can create such an intra- and interhospitals resilient network for pandemic response and alert only if the interdependency is clarified and interoperability is achieved between different information sources/systems (e.g., patient booking system, record system, and beds management system) and different hospitals. However, current practices in hospitals need to be improved for constructing this resilient network due to (1) the loosely connected systems and hospitals, and (2) the lack of systems approach to processing information and making decisions. The great value could be released through integrating multiple information from two flows (patients and resources) and managing healthcare systems from both the same hospital and different hospitals as a whole using digital twins. We have seen that digital-enabled healthcare systems have changed the behaviour of clinicians and patients during the pandemic (Manthorpe, 2020; Solovjova, 2020). For example, the newly released 'NHS Test and Trace' system is helping us approach the end of a nationwide lockdown. DT is more than that, which is "a near-real-time digital image of a physical object or process that helps optimize [...] performance" (Parrott and Warshaw, 2017). The use of digital twins would support systems analyses in a digital-enabled way, which is not only able to integrate multiple information to provide a total solution but can set up different levels of models from sub-systems, systems, to system-ofsystems. This research would develop the novel framework for creating an inter-hospital resilient network for pandemic response to construct a resilient NHS network and provide a practical contribution to information integration, modelling and analyses of patient and resource flow using digital twins and blockchain technology.

\section{RESEARCH HYPOTHESES:}

During the first months of the COVID-19 pandemic, many healthcare facilities and resources were overwhelmed by the number of patients and the need for healthcare services provision (Supady et al., 2021), including sedative medications, personal protective equipment (PPE), and intensive care unit (ICU) staffing and beds. These medical resources can be divided into two categories for allocation optimization, namely renewable resources and consumable resources. The renewable resources are available on a period-byperiod basis, e.g., staffing, ventilators and beds, and the consumable resources are not constrained on a periodic basis but usually have limited availability in total. It thus will be reasonable to propose three hypotheses for modelling the supply-demand relationship.

H1: The demand of medical resources is only dependent on the number and health conditions for patients. 


\section{Lu, Xie, Chen, Ye, Fang, Meng, Pitt and Lin}

H2: The capacities of renewable resources will be kept unchanged.

H3: The supply of consumable resources will be considered as constant.

\section{THE FRAMEWORK OF RESILIENT HOSPITAL NETWORK DEVELOPMENT}

The research process would include the following three steps: 1). identifying information requirements and quantifying interdependencies, including used systems approach for integration and decomposition of healthcare systems, confirmed operation processes of hospital network during COVID-19 and identified Interdependencies for the hospital network; 2). developing a permissioned blockchain prototype for secure, decentralized and coordinated data exchange at intra- and inter-hospital scale; and 3). designing the framework in the local (intra-hospital) scale and the regional (inter-hospital) scale based on dynamic digital twin and blockchain techniques for further network development. These steps would be discussed as follows.

\subsection{Identifying information requirements and quantifying interdependencies}

Complex systems are characterized by having a large number of dimensions, nonlinear or non-existent models, strong interactions, unknown or inherently random plant parameters, time delays in the dynamical structure (Jamshidi, 1996; Eusgeld et al., 2011). Healthcare systems are typically one kind of complex system, where large sets of components are brought together and interact with one another. As shown in Table 1, these healthcare systems can be divided into four levels, namely the system-of-systems, system, sub-system and asset levels (Pimmler and Eppinger, 1994; Senthilkumar and Varghese, 2009; Chou and Tseng, 2010; Eusgeld et al., 2011).

Table 1: Decomposition of healthcare systems

\begin{tabular}{|c|c|c|c|}
\hline Level Sub-level & Definition & Example in healthcare systems & References \\
\hline System-of-systems & $\begin{array}{l}\text { Assembly of multiple, } \\
\text { heterogeneous, distributed, } \\
\text { occasionally independently } \\
\text { operating systems embedded } \\
\text { in networks at multiple levels }\end{array}$ & $\begin{array}{l}\text { Healthcare systems at the regional } \\
\text { scale, forming the inter-hospital } \\
\text { network }\end{array}$ & $\begin{array}{l}\text { Zhang and Peeta, 2011; } \\
\text { Eusgeld et al., } 2011\end{array}$ \\
\hline System & $\begin{array}{l}\text { Assembly of physical sub- } \\
\text { systems for high-level } \\
\text { functions }\end{array}$ & $\begin{array}{l}\text { Hospital, testing centre or vaccine } \\
\text { centre, and their served } \\
\text { communities or areas }\end{array}$ & $\begin{array}{l}\text { Pimmler and Eppinger, } \\
\text { 1994; Rinaldi et al., } \\
\text { 2001; Senthilkumar and } \\
\text { Varghese, 2009; Chou } \\
\text { and Tseng, 2010; } \\
\text { Eusgeld et al., 2011. }\end{array}$ \\
\hline Sub-system & $\begin{array}{l}\text { Geographically distinct entity } \\
\text { created to meet specific high- } \\
\text { level functions for the users of } \\
\text { the system. }\end{array}$ & $\begin{array}{ll}\text { - } & \text { Outpatient } \\
\text { - } & \text { Emergency rooms } \\
\text { - } & \text { Quarantine rooms } \\
\text { ICUs etc. }\end{array}$ & $\begin{array}{l}\text { Pimmler and Eppinger, } \\
\text { 1994; Eusgeld et al., } \\
\text { 2011; Heracleous et al., } \\
2017\end{array}$ \\
\hline Section & $\begin{array}{l}\text { Physical entity created to meet } \\
\text { specific functions for the } \\
\text { system. }\end{array}$ & $\begin{array}{ll}- & \text { Space } \\
- & \text { MEP } \\
- & \text { Furniture } \\
\text { - } & \text { Equipment etc. }\end{array}$ & $\begin{array}{l}\text { Senthilkumar and } \\
\text { Varghese, 2009; Chou } \\
\text { and Tseng, 2010. }\end{array}$ \\
\hline Component & $\begin{array}{l}\text { Physical entity with specific } \\
\text { functions in each section. }\end{array}$ & $\begin{array}{ll}\text { - } & \text { Beds } \\
\text { - } & \text { Ventilators } \\
\text { - } & \text { Pipes etc. }\end{array}$ & $\begin{array}{l}\text { Pimmler and Eppinger, } \\
\text { 1994; Senthilkumar and } \\
\text { Varghese, 2009; Chou } \\
\text { and Tseng, 2010; Saoud } \\
\text { et al., } 2017\end{array}$ \\
\hline
\end{tabular}

The operation management of complex systems has been very challenging due to complex system interdependencies among or within systems and with external environments (Li, 2018). These system 


\section{Lu, Xie, Chen, Ye, Fang, Meng, Pitt and Lin}

interdependencies can be defined as bidirectional or unidirectional relationships at different levels where the output of one item is essential as the input of another one (Rinaldi et al., 2001; Zimmerman, 2001). For example, the interdependency exists between two hospitals when transferring patients.

In order to clarify where the interdependencies exist at the system and subsystem levels, the operation process of the hospital network has been abstracted (Fig.1). These interdependencies are observed in the sequence of operation process in terms of location, service, medical resource and information, based on which it can be further clarified what these interdependencies are in the hospital network.

Many efforts have been made to investigate what kinds of interdependencies are existed in complex systems (Table 2). For instance, Rinaldi et al. (2001) identified four types of system interdependencies between infrastructure systems, including physical, cyber, geographic and logical. Mendonça and Wallace (2006) focused on service and space connections and also defined four categories of system interdependencies, namely input, shared, exclusive or/and colocation. Eusgeld et al. (2011) extended the aforementioned works and looked at different system interdependencies in more detail, where nine types of system interdependencies have been identified, including input, mutual, co-located, shared, exclusive or physical, cyber, geographic, and logical. Saoud et al. (2017) further identified spatial and analytical interdependencies at the asset level.

According to the operation process of hospital network (Fig.1), this research would focus on the spatial, functional, physical, and cyber interdependencies at the system level (i.e., inter-hospital scale) (Table 3), where the spatial interdependency exists if a local event (e.g., COVID-19 pandemic) can create state changes in all systems; the functional interdependency exists when a function changes in one system will affect the services provided by the others; the physical interdependency exists if the state of one system is dependent on the material output(s) of the others; and the cyber interdependency exists if the state of one system depends on information transmitted between systems.

At the subsystem level (i.e., intra-hospital scale), two kinds of interdependencies will be considered in this research (Table 3). The functional interdependency can describe the relationship between services provided by subsystems, and the cyber interdependency can describe the information exchange between subsystems.

Table 2: System interdependencies identified in previous works

\begin{tabular}{lll}
\hline Level & Identified system interdependencies & References \\
\hline System & Four types of interdependencies, including physical, cyber, geographic, and & Rinaldi et al., \\
& logic. & 2001 \\
& Two types of interdependencies, including functional and spatial. & Zimmerman, \\
& & 2001 \\
& Four interdependent conditions defined, including input, shared, exclusive-or, & Mendonça and \\
& and colocation. & Wallace, 2006 \\
& Five types of interdependencies, including physical, informational, geospatial, & Dudenhoeffer \\
& procedural and societal. & et al., 2007 \\
& Four types of interdependencies, including functional, physical, budgetary, and & Zhang and \\
& market and economic. & Peeta, 2011 \\
& Two categories of interdependencies, including location-specific (physical), & Utne et al., \\
& and functional. & 2011 \\
System $\&$ Nine categories of interdependencies, including input, mutual, co-located, & Eusgeld et al., \\
subsystem & shared, exclusive-or, physical, cyber, geographic, and logical. & 2011 \\
& Two kinds of interdependencies defined, including internal and external, where & Heracleous et \\
& the external interdependencies were further represented by physical, cyber, & al., 2017 \\
& geographic, and logical. & \\
& Four types of interdependencies, including stochastic failure propagation, logic, & Goldbeck et \\
& asset organizatio, and resource input. & al., 2019 \\
& Two kinds of interdependencies defined, including spatial and analytical & Saoud et al., \\
interdependencies. & 2017 \\
\hline
\end{tabular}




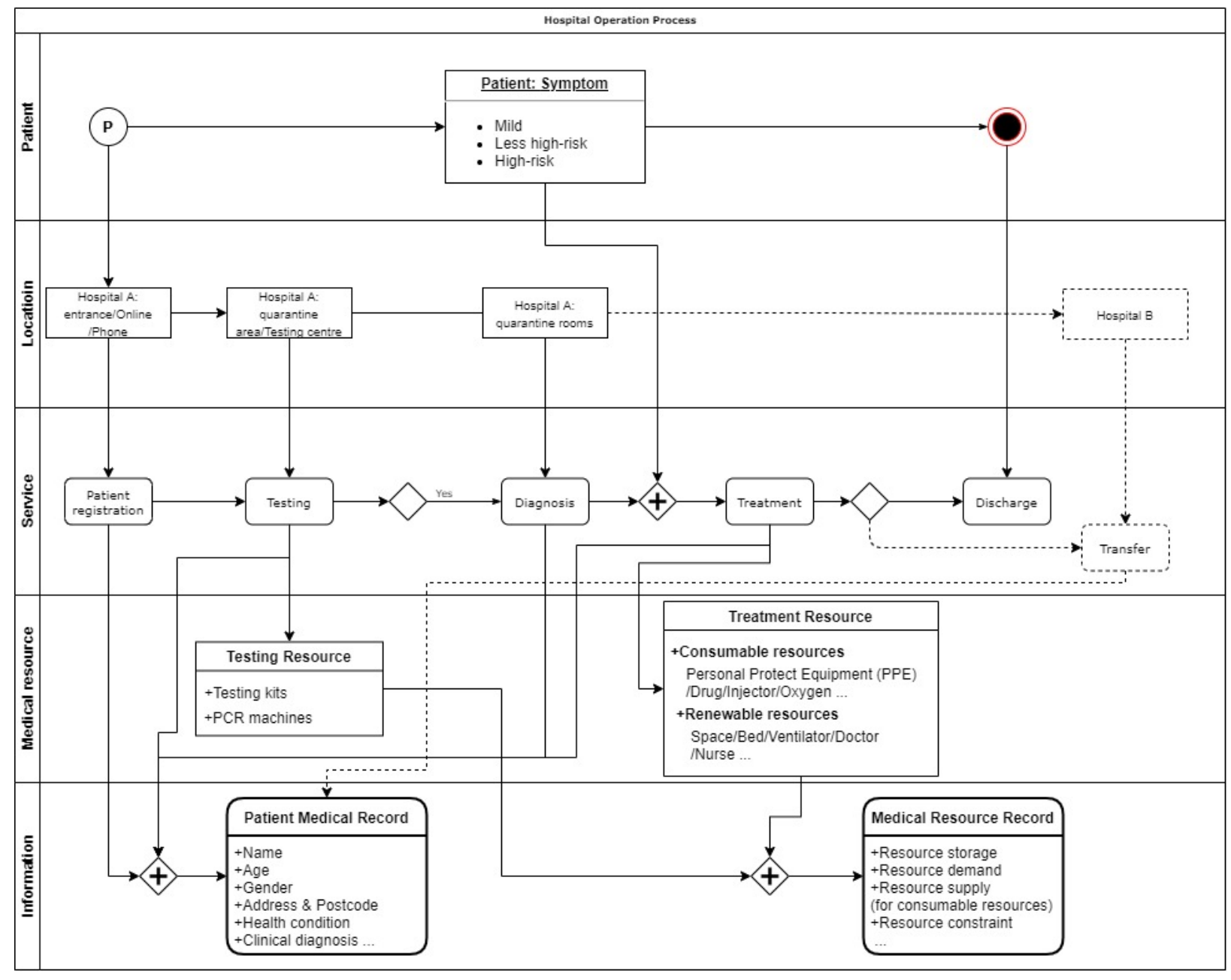

Figure 1: Operation process of the hospital network

Table 3: System interdependencies in the hospital network

\begin{tabular}{|c|c|c|c|c|}
\hline Level & $\begin{array}{l}\text { Types of } \\
\text { interdependency }\end{array}$ & Definitions & $\begin{array}{l}\text { Examples in the hospital } \\
\text { network }\end{array}$ & References \\
\hline \multirow[t]{3}{*}{ System } & Spatial & $\begin{array}{l}\text { A local event can } \\
\text { create state changes in } \\
\text { all systems }\end{array}$ & $\begin{array}{l}\text { The outbreak of COVID-19 } \\
\text { pandemic can affect the hospitals } \\
\text { in related areas (e.g., location in } \\
\text { Fig.1) }\end{array}$ & $\begin{array}{l}\text { Rinaldi et al., } \\
\text { 2001; } \\
\text { Zimmerman, } \\
2001\end{array}$ \\
\hline & Functional & $\begin{array}{l}\text { A function changes in } \\
\text { one system will affect } \\
\text { the services provided } \\
\text { by the others }\end{array}$ & $\begin{array}{l}\text { Hospitals have been specified for } \\
\text { cases in different health } \\
\text { conditions, e.g., Royal London } \\
\text { Hospital for high-risk cases while } \\
\text { others for less high-risk cases } \\
\text { (e.g., service in Fig.1). }\end{array}$ & $\begin{array}{l}\text { Zimmerman, } \\
\text { 2001; Zhang } \\
\text { and Peeta, } \\
\text { 2011; Utne et } \\
\text { al., 2011 }\end{array}$ \\
\hline & Physical & $\begin{array}{l}\text { The state of one } \\
\text { system is dependent } \\
\text { on the material } \\
\text { output(s) of the others }\end{array}$ & $\begin{array}{l}\text { The medical resources can be } \\
\text { requested by other hospitals if } \\
\text { necessary and available (e.g., } \\
\text { medical resource in Fig.1). }\end{array}$ & $\begin{array}{l}\text { Rinaldi et al., } \\
2001 ; \\
\text { Dudenhoeffe } \\
\text { r et al., 2007; }\end{array}$ \\
\hline
\end{tabular}




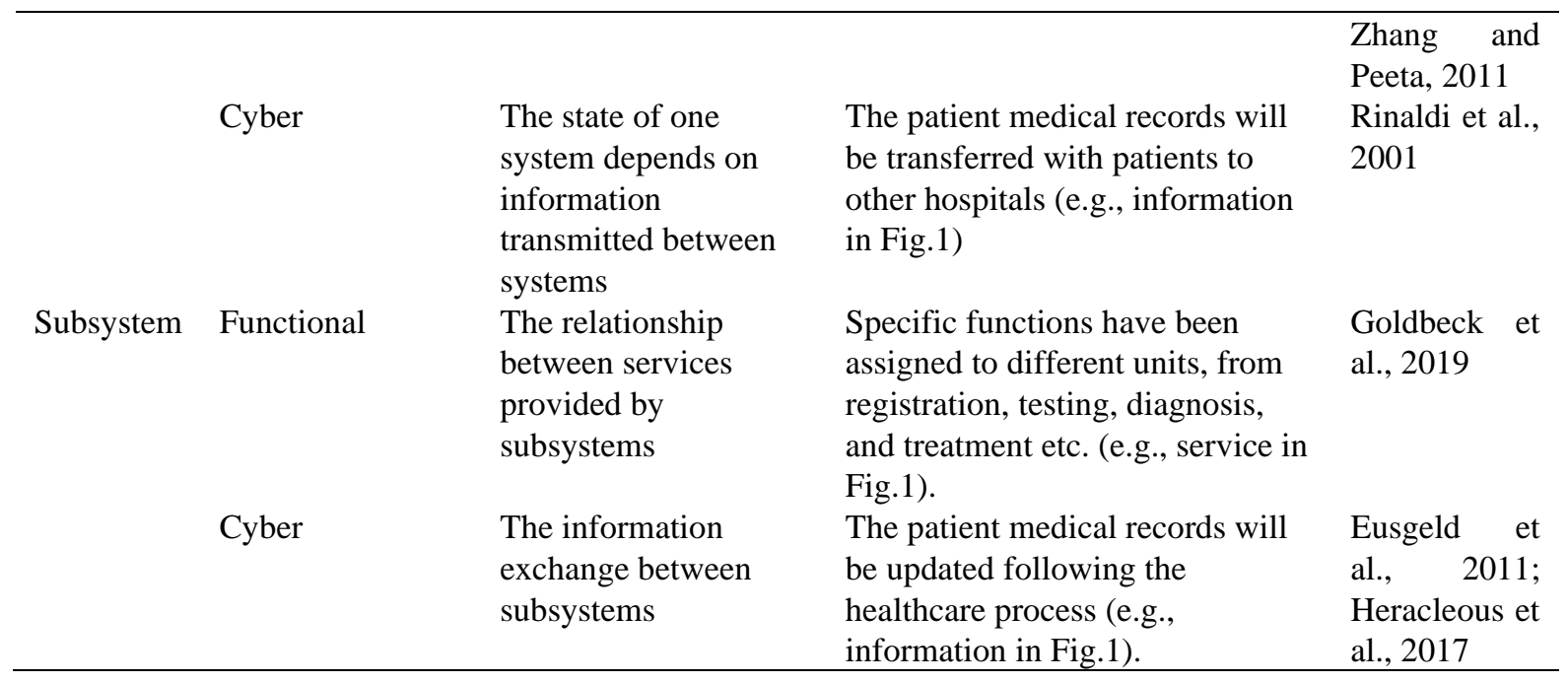

\subsection{A permissioned blockchain prototype development}

As the underlying technology behind Bitcoin, blockchain is known as a distributed public ledger built on "decentralized trust" (Yli-Huumo et al. 2016). Instead of using the conventional centralized client-server architecture, blockchain is identified as a peer-to-peer (P2P) network that publicly or privately distributes blocks and transactions to all users, allowing any type of data to be stored in a reliable and verifiable way. As a responsible and transparent mechanism to store, distribute and exchange health-related data, blockchain technology provides a new way to tackle data privacy, security, and integrity issue in the healthcare sector (Khezr et al. 2019). Comprehensive reviews have been conducted to explore the potential of blockchain technology in massive healthcare applications (Hölbl et al. 2018; Kuo et al. 2017; Mettler et al. 2016; McGhin et al. 2019; Radanović and Likić 2018; Siyal et al. 2019), such as pharmaceutical supply chain, electronic medical record (EMR), remote patient monitoring (RPM), etc.

Under the current scenario, COVID-19 patients are overwhelming the GPs and hospitals. Since blockchain technology enables distributed, encrypted, and secure logging of digital transactions, it can be leveraged nationally to transfer the treatment-related information between patients, doctors, and healthcare providers, meanwhile optimize the medical procedures amongst hospitals in a coordinated way (Chang et al. 2020). Particularly, due to the imbalance distributions between COVID-infected patients and hospital capacities/medical resources, patients need to be flexibly allocated or even transferred between hospitals to reduce strain. It adds extra pressure to existing health information systems forcing medical providers to ensure that electronic health records are shared effectively and securely among remote care locations. Azaria et al. (2016) proposed the concept of Medrec, a decentralized record management system to handle electronic medical records using blockchain technology. MedRec provides capabilities for managing authentication, confidentiality, accountability, and data sharing. The system provides easy access to patients' medical information through a blockchain network that consists of several medical stakeholders that are securing the network utilizing a Proof-of-Work consensus scheme. Dubovitskaya et al. (2017) used a permissioned blockchain for providing data sharing from the medical perspective. In contrast to MedRec, the framework presented in Dubovitskaya et al. (2017) does not require any transaction fees and utilizes a centralized cloud-based storing service to ensure the availability of data. Alternatively, Hussein et al. (2018) focused on enhancing security considerations when sharing sensitive data with the deployment of a discrete wavelet transform and a genetic algorithm technique. In this project, the focus is concentrated on proposing a blockchain-based data-sharing framework to ensure a secure, user-centric approach for sharing and 


\section{Lu, Xie, Chen, Ye, Fang, Meng, Pitt and Lin}

accessing COVID-19 patient information amongst hospitals while preserving patient privacy as much as possible.

Using blockchain, Covid-19 patient's clinical records could be disseminated easily with peers (doctors or hospitals) in the healthcare system. Blockchain comes in many forms, public, private and consortium blockchains, depending on the participants (Zheng et al. 2017). The key requirement of a healthcare system that is working on Covid-19 patients' clinical record collections is to guarantee diverse features such as immutability (tempered-proof), privacy, and consistency. The degrees of openness and decentralization of consortium blockchains are desired in this case (Du et al. 2020). A consortium blockchain includes multiple participants who do not trust each other. Each participant can specify one or more consensus nodes, and a transaction must be confirmed by most of the consensus nodes. Only the participant's consensus nodes have read and write permissions; other external nodes have only incomplete permissions. By combining consortium blockchain with medical information systems, authorized users, mainly hospitals across diverse local communities, can jointly maintain the information in the blockchain network via a consensus mechanism.

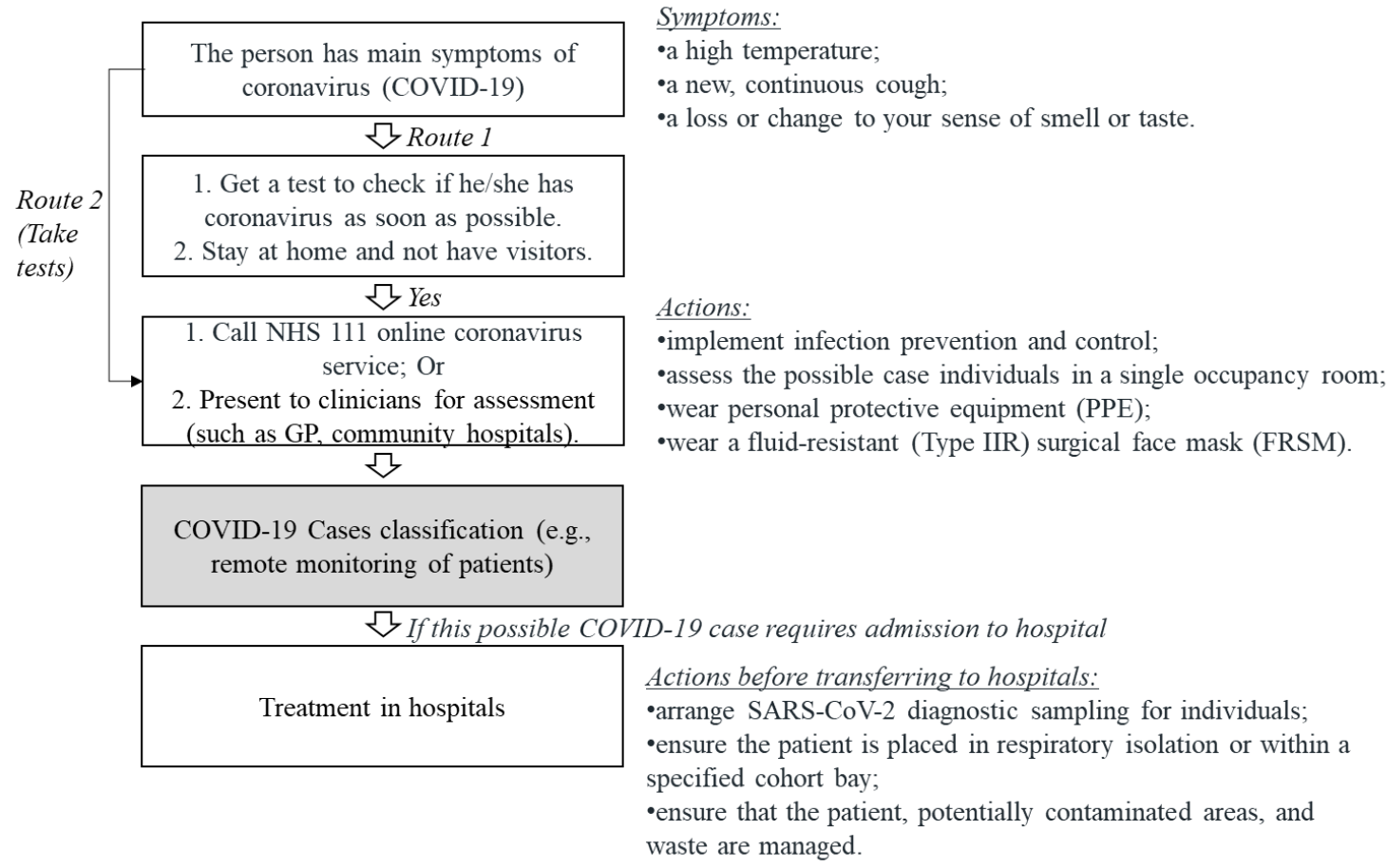

Figure 2: The COVID-19 patients admission strategies in the UK 
Stepdown of infection control precautions and discharging COVID-19 patients
Clinical improvement criteria:

clinical improvement with at least some respiratory recovery absence of fever $\left(>37.8^{\circ} \mathrm{C}\right)$ for 48 hours without the use of medication no underlying severe immunosuppression

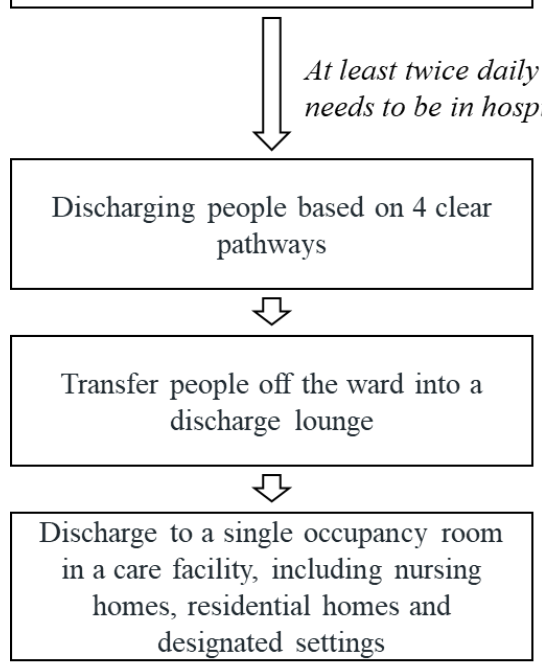




\section{Lu, Xie, Chen, Ye, Fang, Meng, Pitt and Lin}

information-sharing platform is going to be established to create a shared ecology in which better coordination can be achieved between different hospitals during the pandemic (shown as Fig.4). Based on the analysis from section 2.1, business processes were defined to categorize information exchange paradigms beyond the autonomous hospital system between COVID-19 patients, hospitals, regulatory authorities (e.g., medical management departments/organizational resource manager). The paradigms include patient record transfer when the patient is transferred from hospital A to hospital B, and medical resource requests to support resource deployment/redeployment. Confidential sharing processes are enabled to record the information sharing transactions between these users, which will be verified by individual regulatory authorities in the next stage (Kleinaki et al. 2018). Accordingly, the consortium blockchain architecture and the consensus mechanism employed were designed to ensure the accuracy, integrity, security, and efficiency of medical information shared amongst hospitals.

\subsection{This proposed hierarchical framework at the hospital and regional levels.}

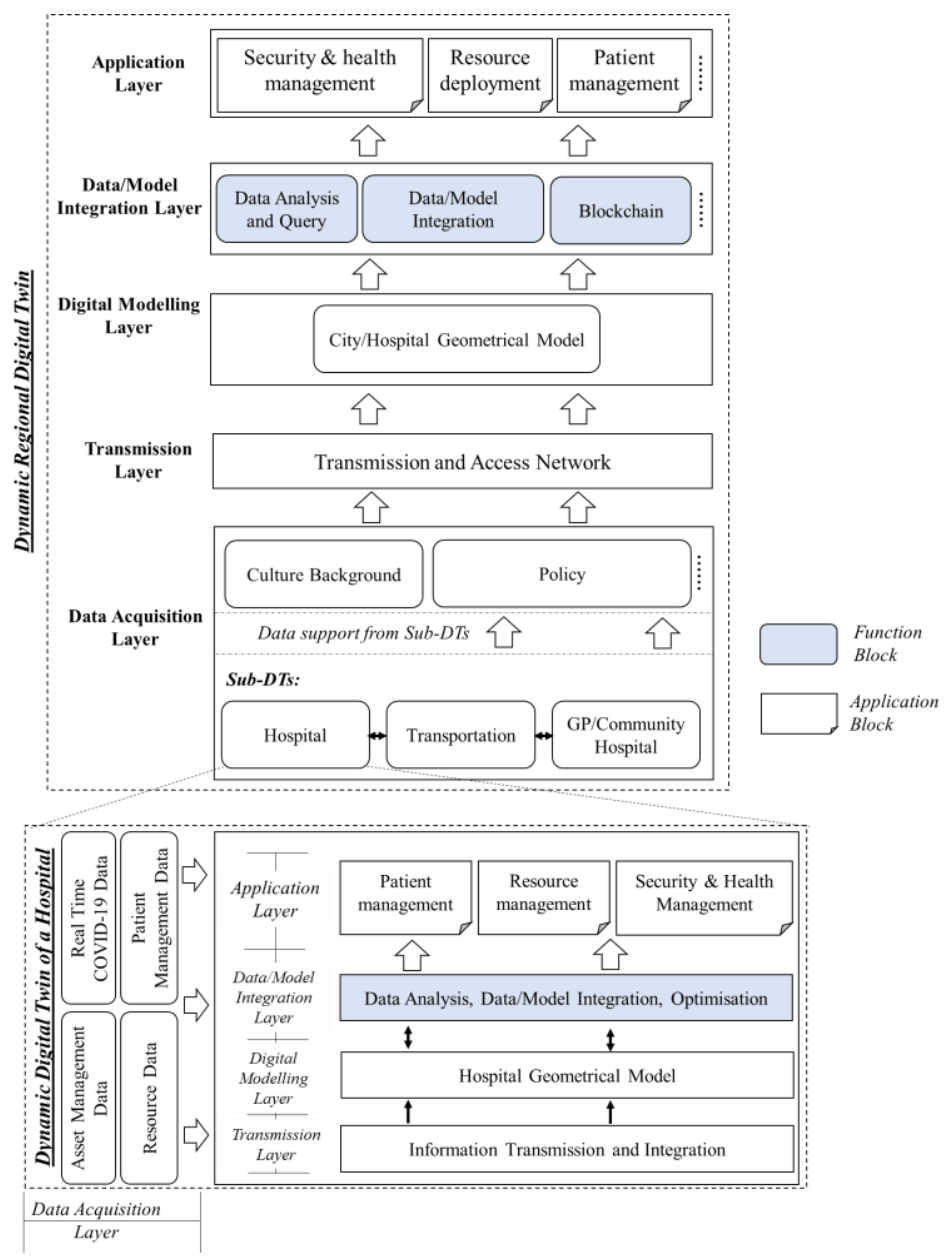

Figure 5: The proposed framwork in the local (intra-hospital) scale and the regional (inter-hospital) scale based on blockchain

This framework (as shown in Figure 5) is comprised of five layers: data acquisition layer, transmission layer, digital modelling layer, data/model integration layer and service layer. Blockchain techniques proposed in the section 2.2 would be embedded in the data/model integration layer and support medical resources deployment at different levels. This framework would integrate different data resources and assets, and further create an inter-hospital resilient network for pandemic response based on blockchain, 


\section{Lu, Xie, Chen, Ye, Fang, Meng, Pitt and Lin}

which would set up innovative ways to best care for patients, protect NHS staff, and support government scientific decisions to beat COVID-19 now and manage the crisis in the future. This framework will be evaluated in the future works.

\section{DISCUSSION AND CONCLUSION}

The main aim of this study is to articulate how blockchain can be used with systems and digital approach to improve the capacity and resilience of NHS healthcare system, beating COVID-19 now and shielding NHS in the future. To do this, and develop well-targeted outputs, this paper identified and clarified critical interdependencies among different hospitals and information systems for patients and resources flows management leveraged at local (intra-hospital) and regional (inter-hospital) scales. Then, we established a blockchain-based data exchange structure that can sufficiently address the access control challenge associated with sensitive healthcare data stored in each individual local dynamic digital twins, and a framework was also developed for the federated and interoperable regional dynamic digital twins via scalable, decentralized, and secure sharing of data. This paper discussed and presented the concepts of the proposed framework. This framework will be tested by real cases in the future and its evaluation will also be performed using hospital data sets.

\section{ACKNOWLEDGEMENT}

The work described in this paper was supported by a grant from the UCL Centre for Blockchain Technologies (CBT) Call for Research Proposals 2020.

\section{REFERENCES}

Azaria, A., Ekblaw, A., Vieira, T. and Lippman, A., (2016). "Medrec: Using blockchain for medical data access and permission management." In 2016 2nd International Conference on Open and Big Data (OBD) IEEE, pp. 25-30.

Chang, M.C. and Park, D. (2020). "How can blockchain help people in the event of pandemics such as the COVID-19?." Journal of medical systems, 44(5), 1-2.

Chou, C. C. and Tseng, S. M. (2010). "Collection and analysis of critical infrastructure interdependency relationships." Journal of computing in civil engineering, 24(6), 539-547.

Dudenhoeffer, D. D., Permann, M. R., Woolsey, S., Timpany, R., Miller, C., McDermott, A., and Manic, M. (2007). "Interdependency modeling and emergency response." In Proceedings of the 2007 summer computer simulation conference, 1230-1237.

Du, M., Chen, Q., Chen, J. and Ma, X., (2020). “An optimized consortium blockchain for medical information sharing.” IEEE Transactions on Engineering Management.

Dubovitskaya, A., Xu, Z., Ryu, S., Schumacher, M. and Wang, F. (2017). "Secure and trustable electronic medical records sharing using blockchain." In AMIA annual symposium proceedings, Vol. 2017, American Medical Informatics Association, pp. 650.

Eusgeld, I., Nan, C., and Dietz, S. (2011). "System-of-systems" approach for interdependent critical infrastructures. Reliability Engineering \& System Safety, 96(6), 679-686.

Goldbeck, N., Angeloudis, P., and Ochieng, W. Y. (2019). "Resilience assessment for interdependent urban infrastructure systems using dynamic network flow models". Reliability Engineering \& System Safety, 188, 62-79.

Heracleous, C., Kolios, P., Panayiotou, C. G., Ellinas, G., and Polycarpou, M. M. (2017). "Hybrid systems modeling for critical infrastructures interdependency analysis." Reliability Engineering \& System Safety, 165, 89-101.

Hussein, A.F., ArunKumar, N., Ramirez-Gonzalez, G., Abdulhay, E., Tavares, J.M.R. and de Albuquerque, V.H.C., (2018). “A medical records managing and securing blockchain based system supported by a genetic algorithm and discrete wavelet transform." Cognitive Systems Research, 52, pp.1-11.

Hölbl, M., Kompara, M., Kamišalić, A. and Nemec Zlatolas, L., (2018). "A systematic review of the use of blockchain in healthcare." Symmetry, 10(10), p.470.

Jamshidi M. (1996). Large-Scale Systems: Modeling, Control and Fuzzy Logic. NJ: Prentice Hall.

Khezr, S., Moniruzzaman, M., Yassine, A. and Benlamri, R., (2019). "Blockchain technology in healthcare: A comprehensive review and directions for future research.” Applied sciences, 9(9), 1736.

Kuo, T.T., Kim, H.E. and Ohno-Machado, L., (2017). "Blockchain distributed ledger technologies for biomedical and health care applications." Journal of the American Medical Informatics Association, 24(6), 1211-1220.

Kleinaki, A.S., Mytis-Gkometh, P., Drosatos, G., Efraimidis, P.S. and Kaldoudi, E., (2018). "A blockchain-based notarization service for biomedical knowledge retrieval." Computational and structural biotechnology journal, 16, $288-297$. 


\section{Lu, Xie, Chen, Ye, Fang, Meng, Pitt and Lin}

Li, S. (2018). "Guest Editorial: Special Section on Reliability, Resilience, and Prognostics Modeling of Complex Engineering Systems." IEEE Transactions on Reliability, 67(1), 2-2.

Mendonça, D. and Wallace, W. A. (2006). "Impacts of the 2001 world trade center attack on New York city critical infrastructures." Journal of Infrastructure Systems, 12(4), 260-270.

Mettler, M., (2016). "Blockchain technology in healthcare: The revolution starts here." In 2016 IEEE 18th international conference on e-health networking, applications and services (Healthcom), IEEE, pp. 1-3.

McGhin, T., Choo, K.K.R., Liu, C.Z. and He, D., (2019). "Blockchain in healthcare applications: Research challenges and opportunities." Journal of Network and Computer Applications, 135, 62-75.

Manthorpe, R. (2020). "Coronavirus: Govt set to release 'contact tracking' app which detects nearby virus carriers". Sky News, 31.

Parrott, A., and Warshaw, L. (2017). "Industry 4.0 and the digital twin: Manufacturing meets its match”. Deloitte. Available from: https://www2.deloitte.com/insights/us/en/focus/industry-4-0/digital-twin-technology-smart-factory.html.

Pimmler, T. U., and Eppinger, S. D. (1994). "Integration analysis of product decompositions". In ASME Design Theory and Methodology Conference, September, Minneapolis, MN, USA.

Radanović, I. and Likić, R., (2018). "Opportunities for use of blockchain technology in medicine." Applied health economics and health policy, 16(5), 583-590

Saoud, L. A., Omran, J., Hassan, B., Vilutienè, T., and Kiaulakis, A. (2017). "A method to predict change propagation within building information model". Journal of Civil Engineering and Management, 23(6), 836-846.

Senthilkumar, V., and Varghese, K. (2009). "Structured methodology to formulate drawing dependency structure matrix for construction design". Architectural Engineering and Design Management, 5(4), 225-248.

Supady, A., Curtis, J. R., Abrams, D., Lorusso, R., Bein, T., Boldt, J., and Brodie, D. (2021). “Allocating scarce intensive care resources during the COVID-19 pandemic: practical challenges to theoretical frameworks." The Lancet Respiratory Medicine.

Siyal, A.A., Junejo, A.Z., Zawish, M., Ahmed, K., Khalil, A. and Soursou, G., (2019). "Applications of blockchain technology in medicine and healthcare: Challenges and future perspectives." Cryptography, 3(1), 3.

Solovjova, L. (2020). "COVID-19: Digital Twins In The Future Of Manufacturing”. Digital Republic. Available from: https://www.digitalrepublicrecruitment.com/2020/05/18/covid-19-digital-twins-\%E2\%80\%AFin-the-future-ofmanufacturing\% $\mathrm{E} 2 \% 80 \% \mathrm{AF} /$.

Utne, I. B., Hokstad, P., and Vatn, J. (2011). "A method for risk modeling of interdependencies in critical infrastructures." Reliability Engineering \& System Safety, 96(6), 671-678.

UK Government (2020). “Coronavirus (COVID-19).” Available from: https://www.gov.uk/coronavirus.

UK's Independent Fact Checking Charity (2020). "We don't know exactly how many NHS workers have died from Covid-19." Available from: https://fullfact.org/health/we-dont-know-exactly-how-many-nhs-workers-have-died-covid-19/.

Yli-Huumo, J., Ko, D., Choi, S., Park, S. and Smolander, K., (2016). "Where is current research on blockchain technology? - A systematic review." PloS one, 11(10), e0163477.

Zhang, P. and Peeta, S. (2011). "A generalized modeling framework to analyze interdependencies among infrastructure systems." Transportation Research Part B: Methodological, 45(3), 553-579.

Zheng, Z., Xie, S., Dai, H., Chen, X. and Wang, H., (2017). “An overview of blockchain technology: Architecture, consensus, and future trends." In 2017 IEEE international congress on big data (BigData congress) IEEE, pp. 557-564.

Zimmerman, R. (2001). "Social implications of infrastructure network interactions.” Journal of Urban Technology, 8(3), 97-119.

\section{AUTHOR BIOGRAPHIES}

QIUCHEN LU is a lecturer (assistant professor) in the Bartlett School of Sustainable Construction at University College London. She earned his Ph.D. in computing in civil engineering from University of Hong Kong. Her research interests include digital twin, artificial intelligence, asset management, and AR/VR technologies. Also, she is the deputy programme lead for the MSc Digital Innovation in Built Asset Management (DIBAM). Her email address is qiuchen.lu@ucl.ac.uk. Her website is https://www.ucl.ac.uk/bartlett/construction/people/dr-qiuchen-lu.

XIANG XIE is a research associate in the Institute for Manufacturing at the University of Cambridge. He earned his PhD in the Deparment of Control Science and Engineering at Zhejiang University. His research interests include data-driven asset management and machine learning in the built environment. His email address is xx809@cam.ac.uk. His website is https://www.ifm.eng.cam.ac.uk/people/xx809/.

LONG CHEN is a Lecturer/Assistant Professor at the School of Architecture, Building and Civil Engineering at Loughborough University. He worked as a Research Associate at Imperial College London and The Alan Turing Institute. He obtained his PhD in Civil Engineering from the University of Hong Kong. His expertise lies within digital construction and operation monitoring, which is established within BIM, digital twin, computer vision, and data-driven approaches. His email address is 1.chen3@lboro.ac.uk. His website is https://www.lboro.ac.uk/departments/abce/staff/long-chen/.

ZHEN YE (Peter) is an associate professor in infrastructure economics and finance at UCL. He holds a university chair 


\section{Lu, Xie, Chen, Ye, Fang, Meng, Pitt and Lin}

professorship at Xiamen University, China. Dr Ye received his MBA from Chicago Booth and his PhD and LLM from the UK. He has published with Structural Change and Economic Dynamics, Journal of Cleaner Production and Competition and Change. His research is multi-disciplinary, and investigates the impact of economic infrastructure on the environment.

ZIGENG FANG is a PhD candidate in the Bartlett School of Sustainable Construction at University College London. He earned his MRes in Architectural Computation from Bartlett School of Architecture at University College London. His research interests include facility management, machine learning, and (data-oriented) strategic asset management. His email address is zi.fang.15@ucl.ac.uk. His website is https://www.ucl.ac.uk/bartlett/construction/people/phd-students/zigeng-fang.

JIAYIN MENG is a PhD student with CSC Scholarship in the Bartlett School of Sustainable Construction at University College London. Her research interests are green finance, environmental economy and green infrastructure investments. Her email address is jiayin.meng.20@ucl.ac.uk.

MICHAEL PITT is a professor in the Bartlett School of Sustainable Construction at University College London. His email address is michael.pitt@ucl.ac.uk. His website is https://www.ucl.ac.uk/bartlett/digital/prof-michael-pitt.

JINYI LIN is a master student of MS.c. infrastructure investment and finance program in the Bartlett School of Sustainable Construction at University College London. She earned her bachelor's degree from Hong Kong Baptist University. Her research interests include infrastructure risk modeling, investment appraisal and asset management. Her email address is jinyi.lin.20@ucl.ac.uk. 